\title{
Graffiti, descolonización y escrituras en fuga (o el contra-bando de lo minoritario)
}

\section{por Rodrigo Ganter S.}

Todas las escrituras presentan un carácter de cerco que le es extraño al lenguaje hablado.

\author{
$R$. Barthes
}

\section{Presentación}

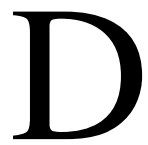

urante los últimos años se ha venido manifestando un fuerte interés de parte de las ciencias sociales y las humanidades (filosofía, crítica literaria, antropología, sociología, historia social, comunicología, etc.) por dar cuenta de una multiplicidad de prácticas culturales que antes habían sido segregadas a un plano espúreo por el canon del discurso académico hegemónico. Los(as) críticos culturales como R. Williams, S. Hall, R. Barthes, D. Hebdige, J. Franco, N. García-Canclini, J. Martín-Barbero, B. Sarlo, N. Richard, K. Oyarzún, etc. han venido instalando, fundamentalmente desde la década del 80 hasta el presente, todo un conjunto de análisis que han operado desdibujando las fronteras y los nichos disciplinares, posibilitando la producción de zonas de saber híbrido, o bien, de contagio transdisciplinario, que inauguran diálogos promiscuos con toda una serie de prácticas discursivas e imaginarios simbólicos polisémicos, en tránsito, precarios, generalmente ligados con el conocimiento de lo subalterno y que han ejercido -en tanto estrategias culturales contra/hegemónicas- toda una virulenta operación de deconstrucción del logos-capitalístico-patriarcal. Operación que tiene uno de sus rendimientos e impactos más significativos en el territorio de lo político/epistemológico; ámbito en el cual deseo situar la textura fronteriza del presente trabajo, revisando particularmente la 
experiencia geo/cultural del graffiti, en tanto agenciamiento escritural alojado en micro-grupalidades juveniles contemporáneas que comienzan a territorializar las memorias discontinuas del descontento (W. Benjamin/M. Foucault), al interior de las diversas tramas metropolitanas latinoamericanas.

\section{(Con)texto geo/histórico y conceptos ${ }^{1}$}

En esta sección se intenta realizar una escueta y general descripción de las diferentes versiones con las que se trabajan -particularmente desde la historia del arte- las nociones ligadas a la práctica del graffiti. Intentando revisitar, al mismo tiempo, las distintas escenas geo/históricas que dan cuenta de la irrupción de dicha experiencia. Para dicho efecto, seguiremos de cerca los aportes de Diego de Jesús (1999).

El término graffiti es impreciso, difuso y es utilizado por ciertos circuitos académicos para designar algunas manifestaciones de la vida cotidiana romana. Las inscripciones encontradas en algunos muros pompeyanos datan en el siglo II d. C., en la Domus Aurea de Nerón (54 -68 d.c.) y en la Villa de Adriano, entre los que se cuentan los letrinalia, inscripciones realizadas en el espacio de las letrinas, que han sido calificados como graffiti por arqueólogos e historiadores. El infinitivo griego grafein así como el latino graffiare tenían en el mundo antiguo la connotación semántica de la inscripción iconográfica y de la textual. Sólo más tarde, ya entrada "nuestra" era, se haría más común cierta denostación a causa de las inscripciones informales, a menudo consistentes en alusiones sexuales o escatológicas, mediante raspaduras o pintura en los espacios públicos de la antigua ciudad romana.

La acepción moderna del término graffiti (nominativo plural del término latino graffitus) se debe a las investigaciones que en la ciudad de New York estudiaron el fenómeno de las pinturas realizadas sobre los vagones del metro y en las paredes de los barrios marginales de esta ciudad utilizando únicamente pintura en spray en sus formatos comerciales de

1 Sección que forma parte de un apartado mucho más amplio sobre el tema del graffiti y que a su vez se inscribe en el contexto de un trabajo de investigación sobre "Memoria, Cultura y Nuevas Narrativas Juveniles", que actualmente desarrollamos en el departamento de sociología de la UCSH en co-laboración con Raúl Zarzuri. 


\section{Graffiti, descolonización y escrituras en fuga / Ganter}

venta al público, cuyos fabricantes, desde luego, nunca contemplaron esta posibilidad de uso. Ahora, la palabra graffiti es utilizada actualmente para referirse a cualquier escritura mural, imágenes, símbolos o marcas de cualquier clase y en cualquier superficie ${ }^{2}$, sin importar la motivación del escritor(a).

Por otra parte, diversos son los ejemplos que visita A. Rama en su "Ciudad Letrada "(1985) para dar cuenta de la presencia significativa en América Latina del fenómeno graffiti ${ }^{3}$ durante los siglos XVI, XVIII y XX, destacando como una escritura y un discurso que desafía al poder en tanto éste restringe el carácter heterónomo de la escritura a un léxico fijo y lineal.

La división genérica básica viene definida, no obstante, por el contexto geo/cultural de origen. Contexto que, a la vista de las implicaciones que conlleva, supone numerosos patrones culturales heredados que caracterizan las tipologías. Según Diego de Jesús, la división señalada por las investigaciones actuales suele ser entre el graffiti francés y el graffiti norteamericano. El primero posee la tradición de toda la escritura mural informal anteriormente descrita. Sin embargo, esta variedad hereda los usos de reivindicación política y social que se forman durante los últimos años sesenta en Francia.

El modelo francés responde básicamente a un tipo de graffiti donde el componente verbal es acusadamente mayoritario y que tiene su exponente más conocido y emblemático en el ingente corpus de las calles de París con ocasión de la revuelta estudiantil de 1968. Esta modalidad grafítica dirige su ingenio a la elaboración verbal, es heredera de una amplia tradición de pensamiento filosófico, poético y humorístico en forma de máxima y entre otros rasgos, se despreocupa usualmente de la elaboración plástica del texto, concentrándose en el plano de su contenido.

Por otra parte, el modelo americano, obviamente identificado a partir

2 De ahí que la propia superficie de este texto aspire (inspire y conspire) a configurar, más que un articulado de citas organizadas desde los muros de la gramática académica con-vencional, una metáfora y un gesto político como aquel que inscribe el graffiti al interior del texto delimitado por las ciudades de la catástrofe.

3 Episodios situados en México, Perú y Buenos Aires, Uruguay, donde el graffiti es catalogado como escritura anónima y clandestina, que se presenta habitualmente con faltas de ortografía, o bien, que da testimonio de la opinión de personas marginadas de las vías legales, ajenas al cultivo de la misma 
de los famosos graffiti de New York, irrumpe con una función bastante diferente. Es decir, sustancialmente desligado de la tradición de pensamiento hegemónico/intelectual o del arte oficial y mucho más expuesto a las influencias de los medios de comunicación modernos, acentuando así el desarrollo formal y la experimentación técnica: el spray es, en efecto, el instrumento asociado a este modelo.

La llegada de esta corriente a Europa, a principios de los ochenta, se ve favorecida por la influencia del llamado Hip-Hop, movimiento contra la violencia, la droga y el racismo, configurado a partir de la Zulu Nation forjada por Afrika Bambaataa en 1974 con idénticos objetivo. El HipHop extendió el graffiti neoyorquino en el interior de los EE.UU. Y sobre todo lo internacionalizó, al basar su ideario proselitista en este medio de expresión al mismo tiempo que en la música rap.

En busca de la diferencia y de la producción de subjetividades migratorias, la gente joven de procedencia afroamericana y latinoamericana, empezaron a utilizar, en la ciudad de New York, un viejo modo de expresión, el graffiti, con códigos propios, sobre las áreas que les eran accesibles: los muros de las calles y de los túneles del metro, que definían cotidianamente el espacio de su existencia urbana. Transgrediendo constante e intencionadamente los patrones estéticos hegemónicos, las rutinas perceptivas del ojo transeúnte y la propiedad privada inmobiliaria; el graffiti se convirtió en una exitosa y eficaz táctica deconstructora (Derrida) utilizada por las narrativas fronterizas y antihegemónicas, con el objeto de hacerse oír e instalar una gramática tenue e intrincada, capaz de resistirse al formateo metropolitano programado por los libretos del verosímil occidental.

\section{La colonización discursiva en el sistema capitalista/patriarcal}

No es casualidad comenzar esta sección acoplando, en el precedente título, dos sistemas canónicos de subordinación de las prácticas polimorfas (resistencias) en occidente, producidas por múltiples potencias subjetivas y susceptibles de ser cartografiadas al interior de las distintas 


\section{Graffiti, descolonización y escrituras en fuga / Ganter}

economías discursivas del poder.

En ese sentido, se hace necesario partir señalando que el patriarcado ${ }^{4}$ constituye una estructura básica no sólo en las sociedades premodernas, sino que también de las sociedades modernas y poscoloniales. Es decir, en tanto estructura de poder parece ser coextensivo a una variedad de modos de producción: esclavista, feudal, capitalista, etc. No obstante, el poder del patriarca en las sociedades contemporáneas se despliega ${ }^{5}$, a diferencia de las sociedades tradicionales, en una intrincada red de dispositivos institucionales descentralizados (familia, escuela, medios de comunicación, estado, etc.) donde el dispositivo masculino tradicional controla, en gran medida, la organización molar y molecular de la sociedad: cultura, economía, política, etc.

Ahora, el rendimiento político más importante de dicho sistema se inscribe en el proceso la naturalización de un modelo hegemónico de familia, donde dicha institución aparece como una unidad económico/ social organizada a partir de relaciones de consanguinidad y con una división sexual del trabajo en la cual el hombre es el proveedor, mientras que la mujer y los hijos dependen económicamente del primero; ligando discursivamente a las mujeres con la naturaleza y a los hombres con la cultura. Lo que finalmente se traduce en un disciplinamiento cultural de los roles masculinos y femeninos al interior de las sociedades occidentales que subordina el lugar de la diferencia: mujeres, locos, niños, jóvenes, homosexuales, enfermos, ancianos, etc.; rentabilizando económicamente los cuerpos pero domesticándolos políticamente (Foucault, 1992) .

Este discurso se trenza poderosamente con el discurso que instala la racionalidad capitalista, a partir del cual los cuerpos de los individuos son distribuidos según el lugar que ocupan frente a los medios de producción; y donde la familia nuclear se convierte en el dispositivo de mayor

4 La instalación de esta noción se inscribe al interior de una operación política de recuperación de la dinámica de la conflictividad en el campo de las humanidades y las ciencias sociales por parte de los saberes feministas, frente a la proliferación de discursos de tono complaciente al interior de dicho campo de discusión, donde parece desconocerse la vigencia de tal práctica cultural en nuestras sociedades.

5 A diferencia de las sociedades tradicionales donde la dominación se ejercía de modo centralizado (Foucault, M. 1992) 
octanaje para la reproducción de la fuerza de trabajo necesaria para la propulsión y expansión del capital.

Pues bien, no obstante la ubicuidad del tejido de relaciones que ha ido manofacturando geo/históricamente el discurso patriarcal, es preciso aludir también a sus heridas y repliegues en las sociedades contemporáneas; para ir avanzando, en un momento posterior, hacia el influjo de su genealogía como tecnología de silenciamiento y colonización de las gramáticas heterónomas; cuestión que constituye, para el presente trabajo, un campo parcial de autoconvocación y experimentación escritural.

Es importante ir puntualizando algunos supuestos tratados hasta aquí. El protocapitalismo de producción/acumulación continúa insuflando al patriarcado fundamentalmente por tres motivos: la familia es la unidad básica de consumo; las mujeres recluidas en el espacio privado son disciplinadas en las funciones reproductivas de la fuerza de trabajo; las mujeres disminuyen el costo del trabajo para el capital, pues los servicios entregados al hombre no constituyen trabajo remunerado.

Sin embargo, tal análisis parece más pertinente para el capitalismo primigenio que para el caso del capitalismo contemporáneo, puesto que el modelo de familia hegemónico/patriarcal, en el marco de la actual racionalidad capitalista, se ha visto minado de manera fundamental e irreversible. Prueba de ello lo configuran una serie de indicadores: incremento de los divorcios, separaciones y crisis matrimoniales, proliferación de los hogares monoparentales y/o emergentes, aumento de los niños/as nacidos fuera del matrimonio, etc.; lo que nos estaría señalando la emergencia de un nuevo marco de relaciones, donde la autoridad ejercida por un hombre adulto al interior de la familia se ve poderosa y crecientemente desdibujada de la escena sociocultural contemporánea.

Ahora, la crisis del modelo familiar patriarcal -donde el Movimiento Feminista y la perspectiva de Género han jugado un rol preponderante- no implica necesariamente la crisis del patriarcado como un sistema ideológico, es decir, como sistema de creencias y significados culturales que configuran un potente discurso que coloniza y formatea la subjetividad contemporánea en nuestras sociedades, garantizando la reproducción 


\section{Graffiti, descolonización y escrituras en fuga / Ganter}

misma de la sociedad que incuba dichas representaciones. Sería ingenuo sostener que las heridas estructurales terminaran por desangrar el cuerpo del patriarca, es posible que puedan perforar y hacer más permeable su anatomía, pero su discurso aún posee textura hegemónica bajo la corteza cultural, incluso al interior de aquellas familias o sociedades con modelos emergentes.

Pero entremos en nuestro tema. El lenguaje es representado aquí como un orden simbólico/cultural, en ese sentido, constituye una práctica atravesada por el poder (Grau, 1997), un ejercicio de colonización (Mignolo), pues el sujeto que nombra coloniza el territorio que designa y transforma en objeto lo que ha delimitado en su acto de habla. Así, mujeres, esclavos, homosexuales, niños, jóvenes, ancianos, locos, etc. son colonizados por la lengua del patriarca y subordinados a hablarla para ser incluidos en el mercado de representaciones e intercambios lingüísticos.

El lenguaje viene a operar como instrumento de acción y poder (Bourdieu, 1985), como voluntad de comunicación, pero también como voluntad de colonizar sentidos y significados en función de determinados intereses particulares. De ahí que el lenguaje no sólo nombra, puesto que en tal operación hay implícita toda una tecnología de disciplinamiento cultural (Foucault, 1992), a través de la cual se busca inscribir en los cuerpos una ley (¿del padre?), una política general de la verdad (Foucault); donde se define, se jerarquiza, se clasifica, se distribuye, se domestica y rentabiliza la experiencia de la anomalía.

Es el discurso del patriarca, en tanto metanarración (Lyotard, 1995), el que le otorga estatuto lógico/universal al locus masculino e impide a las lenguas minoritarias expresarse en su propio léxico, segregándolas al ámbito de la otredad, pues cuando hablan los subalternos hablan los otros. Encapsulado dichas hablas en el lugar de la oscuridad, de lo intrincado, de los flujos y los efluvios impuros de la carne, por lo mismo al lugar que se debe colonizar, desentrañar e incorporar -mediante estrategias hermenéuticas- a la gramática logocéntrica instalada en el nombre del padre, es decir, a la política de la verdad que opera al interior de dicha estructura de poder, donde son autorizados cierto tipo de representaciones discursivas ligadas a lo masculino/hegemónico y se invalidan las 
otras discursividades ligadas preferentemente a la posición que ocupan mujeres, niños, jóvenes, locos, homosexuales, etc.

Ahora, pensar con este tipo de lectura, que en alguna medida se sustenta en esquemas que podríamos llamar binarios - oposicionales (lo uno versus lo otro), también tiene sus riesgos, pues pensar desde la especificidad de la otredad y/o marginalidad (identidad propia), nos puede llevar a legitimar estructuras canónicas de pensamiento, donde la proclamación de la diferencia a partir de la condición de lengua silenciada supone finalmente la introyección de la obediencia a la lengua colonial. De ahí la necesidad de ir más allá de los esquemas polares con el propósito de deconstruir los discursos hegemónicos y continuar avanzando en el esbozo de una perspectiva crítica que sitúe al lenguaje, a la escritura ( graffiti), en el campo de los conflictos geo/culturales y la producción de significados fronterizos, capaces de disputar con el verosímil construido por la ficción colonizadora de un saber desprovisto de inquietudes en torno a las políticas de la cotidianeidad y experiencia.

\section{El graffiti como escritura incardinada}

Partamos consignando junto a Patrizia Violi (1990) que cualquier teoría del lenguaje es también una teoría del sujeto. No obstante, para la lingüística de Saussure y para los estructuralistas en general, el lugar del sujeto es segregado al del sistema, pues constituye un riesgo que hace tambalear el andamiaje a partir del cual se sostiene el proyecto de la cientificidad.

Ahora, intentemos esbozar un mapa (con la ayuda de Violi) que dibuje las líneas generales de dicha tensión, no con el propósito de profundizar en ella, pues no constituye el núcleo central de este trabajo, sino más bien un pre-texto que opera como táctica introductoria a la discusión que pretende abrir la presente sección.

Para la lingüística saussuriana no habría lugar para el sujeto empírico, ya que éste constituiría una categoría contaminada, impertinente desde el punto de vista teórico y que se mueve más bien en el ámbito de la exterioridad del sistema lingüístico. De este modo, el sujeto hablante y su conciencia de sujeto hablante se verían imposibilitados de encontrar 


\section{Graffiti, descolonización y escrituras en fuga / Ganter}

espacio dentro de la teoría; imposibilidad que se expresaría en la dificultad de los estructuralistas para pasar de una teoría del signo a una del discurso. Sin embargo, la gramática generativa (Chomsky) va un poco más allá y decide asumir al sujeto como una categoría que configuraría un presupuesto necesario para la teoría. Aunque dentro de este último esquema se considera un sujeto del enunciado y no un sujeto de la enunciación, vale decir, sujeto que piensa, pero no sujeto que habla.

Pero es sólo con la lingüística pragmática (Benveniste) donde hay sujeto al interior del proceso lingüístico: no hay subjetividad fuera del lenguaje, pues sólo el lenguaje funda realidad y el sujeto se funda en el acto de enunciarse («yo»). De ahí que el sujeto sea sujeto del discurso y sujeto de la enunciación, como ya lo habíamos planteado en las secciones precedentes.

Un punto fundamental de esta discusión se configura a partir de la inflexión propuesta por P. Violi (1990), donde se critican las concepciones que montan sus modelos de sujeto sustentándose en componentes lógico abstractos (historia), reduciendo los aspectos sensibles (pre-historia) de la subjetividad al de las manifestaciones puramente racionales, perdiéndose así la posibilidad de producir una reflexión de la diferencia, esto es, corporeizada/sexuada, que (re)componga experiencia de vida y pensamiento, en otras palabras, que comprenda al sujeto de la enunciación ya no como una entidad abstracta, sino que como una identidad incardinada física y geo/históricamente. Ahora, es precisamente en este punto donde comienza a filtrarse la temática que pretende abordar el presente escrito.

Desde una dirección bastante emparentada con la visión anterior, Julia Kristeva (1981), participante del grupo Tel Quel (68/francés), es quien comienza a hablar de sujeto en proceso, que designaría al sujeto del lenguaje poético, frente al lenguaje científico que reduce al sujeto a un solo punto o al punto de vista del sujeto trascendental. Kristeva utiliza el término semiótica, en un intento de ir más allá del plano de la recursividad (construcciones generativas) y de regresar al sujeto ya no cómo lugar de referencia -punto vacío- sino como concreción geo/histórica, es decir, devolviéndole su materialidad: eso es el sujeto en proceso. 
Así, Kristeva reivindica el lenguaje materno, la lengua materna: el roce, la fricción, la sensibilidad, el tacto, la huella que traza el mapa político de la piel, el acontecimiento minúsculo de una línea que bifurca su memoria en la palma de una mano, la experiencia del cuerpo; lenguaje que olvidamos automáticamente en la medida que aprendemos a hablar.

Paradójicamente es la madre la que nos enseña a hablar y con ello introyecta la lengua del padre, la ley del padre, contribuyendo, en ese proceso, a su propia pérdida, a su propia desaparición.

Bajo este esquema el lenguaje supone siempre una renuncia, una sustitución de lo real [¿el cuerpo como lo real?], una pérdida. Pero, al mismo tiempo el lenguaje lo hace presente a partir de su ausencia (Lacan). Configurándose, entonces, una tensión: podemos comunicarnos, humanizarnos en la conversación, en el habla, sin embargo, al mismo tiempo que hablamos de la realidad la matamos un poco, la hacemos desaparecer. Nos humanizamos en la palabra y simultáneamente nos distanciamos de lo real, pues la palabra es la inexistencia manifiesta de aquello que designa (Mallarme). En esa capacidad de abstracción, lo real nunca puede estar presente, lo real está más allá, o como diría Blanchot: la verdad en la ausencia.

Pero, para Kristeva la poesía rompería la ley y el orden del padre (experiencia del afuera), puesto que el lenguaje poético es el uso del lenguaje como valores, en lugar de signos, o sea, libera el componente pulsional, reactiva lo reprimido pulsional y en ese gesto retorna la posibilidad de constitución del sujeto en proceso, para quién la palabra no es únicamente signo, sino discurso, significación, textura. Abriéndose la posibilidad, a partir de esta inflexión, de poder pensar el lugar del lenguaje y el habla como escritura.

Ahora, el concepto de escritura ha sido trabajado por Derrida (1971) y aplicado por el grupo Tel Quel (Kristeva). En ese sentido, gramma denota la marca de la escritura, raíz que utiliza Derrida para hablar de gramatología:, es decir, ciencia de la escritura, donde opera una sustitución de la lingüística, es decir, ciencia del habla: logos. 


\section{Graffiti, descolonización y escrituras en fuga / Ganter}

La metafísica siempre asignó al logos el origen de la realidad, ya que desde dicha visión la palabra hablada está más cerca de la conciencia, mientras que la transcripción escritural (graffiti) está mas cerca de lo sensible, de lo pre-lógico (Violi, 1990), de lo pre-cognitivo. Así, el significado se encarna en el significante fónico con más pureza que el significante gráfico. Pero, la ley del logos a empezado a ser transgredida en la práctica, y el espacio que más virulentamente lo ha venido minando es el espacio de las sensibilidades características de las posmodernidad (Lyotard), en tanto espacio de producción de las diferencias. No obstante, dicha transgresión es una transgresión con límites, pues existen contextos materiales de producción escritural, aunque siempre se crea un excedente, es decir, disidencias, deseos migratorios que no alcanzan a ser catalizados por la reproductibilidad técnica, un más allá de los medios; por ello la posibilidad de resignificar la cultura siempre está abierta, la posibilidad de saltar al abismo siempre se encuentra latente, aún cuando el resultado no sea otro que el de una nueva suplantación de la experiencia política de la alteridad.

De ahí la convocatoria y la espera del presente trabajo en relación con la temática del graffiti, pues dicha práctica escritural configura una textura atravesada por múltiples puntos de fug $a^{6}$ frente a las gramáticas canónicas. O sea, una falla maquínica, una filtración, una pérdida, un escape de colores y temblores que se escurren entre las canillas de la noche, o bien, un equívoco que no alcanza a dar cuenta de sí mismo, pues no tiene cuenta, no cuenta, descuenta; no tiene economía ni ahorro, al contrario, derrocha y dilapida manchas multitudinarias y ambiguas hasta desalojar nuestro ojo del mono-tono y empobrecido paisaje perceptivo reorganizado funcionalmente por la seguridad de la ciudadela modernizada.

Pero vayamos por parte: en general se puede considerar al graffiti como unidad de creación artística en lo que a sus valores expresivos y técnicos se refiere, la cual es reproducida por microgrupalidades concretas, generalmente juvenil, cuyos miembros se reconocen entre sí por su actividad más o menos clandestina y por adherir a una práctica cultural de carácter minoritario, es decir, que de un modo u otro produce un discurso polifó-

6 Escribir es trazar líneas de fuga, dirá Deleuze (1997), más aún la escritura por sí misma, cuando no es oficial, se encuentra forzosamente con "minorías". 
nico, pero que generalmente enfatiza un tono de disidencia o descontento con el orden social "dominante".

N. García-Canclini (1995), lo define como una escritura territorial de la ciudad, un medio sincrético y transcultural a través del cual se funden palabra e imagen en un estilo discontinuo. Bajo esta perspectiva, el graffiti sería una táctica escritural minoritaria, desterritorializada, efímera y fronteriza, que busca inaugurar nuevos agenciamientos y velocidades entre la política y la cotidianidad.

Se puede sostener también que el graffiti, en tanto práctica cultural intersticial, constituye un potente dispositivo de producción de significados críticos y matices multiculturales, es decir, de producción de alteridades y de subjetividad disidentes, que generalmente son de compleja lectura/interpretación para quienes se encuentran fuera de su circuito de producción simbólica. Así, se puede llegar a pensar a la comunidad de escritores de graffiti como un colectivo de creación cultural cerrado y con códigos gramaticales y semánticos altamente compartimentados.

De este modo, el graffiti en tanto práctica cultural minoritaria, puede ser leído como escritura posicionada socio/históricamente, localizada geo/históricamente, dado los referentes grupales en los cuales se incardina y contextualiza dicha experiencia, pero simultáneamente como una escritura descentrada y discontinua, una escritura profana, que transgrede multiformemente la épica muralista del acontecimiento urbano global. Por lo mismo, una escritura y una potencia capaz de con-vertir (sub-vertir) un texto, un muro o una ciudad entera, en un mapa o un cuerpo que no se reduzca a la hiper-funcionalización de sus procesos biopolíticos, sino que multiplique el devenir de su vitalidad a partir de fugas y derroches (Bataille), que inventen nuevos planos y registros de con-vivencialidad urbana.

Y estando vigilantes a la esencialización de las experiencias micropolíticas y culturales como las descritas en esta superficie mural de materialización de los discursos académicos, también es posible pensar dicha práctica cultural como una instancia fuertemente emparentada con tácticas poético/estéticas, con el componente pre-lógico, la sensibilidad, 


\section{Graffiti, descolonización y escrituras en fuga / Ganter}

los colores, las formas y la corporalidad; con la dimensión experiencial de la alteridad, con la textura afectiva inscrita sobre los bordes capilares del hipertrofiado Santiago, y que en ese trazado lo va reinventando desde los descalces de la modernización.

En ese sentido, fuertemente solidaria con aquel excedente al cual se hacía alusión anteriormente, con ese plus valor, con ese plus color, o bien, con ese deseo oblicuo y fluorescente que no alcanza a ser rentabilizado por la lengua del padre, constituyendo así una experiencia susceptible de pensarse al interior de la experiencia del afuera en el lenguaje (Artaud/ Foucault); y -por que no- como el gesto que deconstruye el habla en tanto lugar de sustitución de lo real: la prótesis ${ }^{7}$; y que en su fulgurante archi-textura de colores y volúmenes va evocando toda una economía política del derroche, que multiplica una gama infinita de silencios que pintan el umbral de su propio decir.

\section{De lo leído y lo referido}

- Bourdieu, P. : ¿Qué significa hablar?, Akal, Madrid, 1985.

- De Jesús, D. : danton@ arrakis.es 1999.

- Deleuze, G.: Diálogos, Pre-textos, Valencia, 1997.

- Derrida, J.: De la gramatología, Siglo XXI, Bs. As., 1971.

- Foucault, M.: Microfísica del poder, La Piqueta, Madrid, 1992.

- García Canclini: Culturas Híbridas: estrategias para entrar y salir de la modernidad, Sudamericana, Bs. As., 1997.

- Grau, O.: Discurso, Género y Poder, Lom, Santiago, 1997.

- Kristeva, J.: Semiótica, Fundamentos, Madrid, 1981.

- Lyotard, J.: La condición postmoderna, REI, México, 1990.

- Rama, A.: La ciudad letrada, en Cultura urbana latinoamericana, Clacso, Bs. As., 1985.

- Violi, P.: Sujeto lingüístico y sujeto femenino, en Feminismo y teoría del discurso, Cátedra, Madrid, 1990.

7 Del gr. pro, delante; y thesis, colocación 